\title{
XRCC4 rs6869366 polymorphism is associated with susceptibility to both nicotine dependence and/or schizophrenia
}

\author{
Sacide Pehlivan¹, Mehmet Atilla Uysal2, Nazan Aydin², Ayse Feyda Nursal3, Mustafa Pehlivan', Hazal Yavuzlar5, \\ Ulgen Sever ${ }^{1}$, Selin Kurnaz ${ }^{1}$, Fatih Kasım Yavuz ${ }^{2}$, Suna Uysal2, Pinar Cetinay Aydin ${ }^{5}$
}

\author{
1 Department of Medical Biology, Istanbul University, Istanbul Faculty of Medicine, Istanbul, Turkey. \\ 2 Department of Chest Diseases, Yedikule Hospital for Chest Diseases and Thoracic Surgery Training and Research Hospital, Istanbul, Turkey. \\ 3 Department of Medical Genetics, Hitit University, Faculty of Medicine, Corum, Turkey. \\ ${ }^{4}$ Department of Haematology, Gaziantep Univesity, Faculty of Medicine, Gaziantep, Turkey. \\ ${ }_{5}^{5}$ Department of Psychiatry, Bakirkoy Research and Training Hospital for Psychiatry, Neurology and Neurosurgery, Istanbul, Turkey.
}

Received: 01/04/2018 - Accepted: 06/05/2018

DOl: 10.1590/0101-60830000000157

\begin{abstract}
Background: Oxidative stress induced DNA damage has been assumed to contribute to the etiopathogenesis of schizophrenia (Sch). Smoking prevalence was more common in patients with Sch. The X-ray repair cross-complementation group 4 (XRCC4) gene plays an important role in the repair of DNA double-strand breaks. Objective: The purpose of this study was to investigate whether XRCC4 rs6869366 polymorphism has a relationship both in nicotine dependence (ND) and Sch+ND risk. Methods: One hundred and four patients with Sch+ND, 133 subjects with ND only and 70 healthy controls were enrolled in the study. XRCC4 rs6869366 polymorphism was analyzed using PCR-RFLP assay. Results: The frequency of XRCC4 rs6869366 GG genotype was more common in the ND and Sch+ND group than controls $(\mathrm{p}=0.001$ and $\mathrm{p}=0.001$, respectively). XRCC4 rs6869366 TT genotype was lower in both ND and Sch+ND group compared to controls $(\mathrm{p}=0.001$ and $\mathrm{p}=0.001$, respectively). Also, XRCC4 rs6869366 G allele was higher in Sch $+\mathrm{ND}$ group than controls $(\mathrm{p}=0.001)$ while XRCC4 rs6869366 T allele was lower in ND group than healthy controls ( $\mathrm{p}=0.001)$. XRCC4 rs6869366 GT genotype was lower in ND group than control group $(\mathrm{p}=0.003)$. Discussion: These results suggested that the XRCC4 rs6869366 polymorphism G related genotype/allele was associated with susceptibility to both ND and Sch+ND in a Turkish population.
\end{abstract}

Pehlivan S et al. / Arch Clin Psychiatry. 2018;45(3):53-6

Keywords: DNA repair, Schizophrenia, nicotine dependence, XRCC4.

\section{Introduction}

Schizophrenia (Sch, OMIM181500), manifested by delusions, hallucinations, altered cognition, emotional reactivity, and disorganized behavior ${ }^{1}$, is one of the most debilitating and heterogeneous neuropsychiatric diseases. It occurs in about $1 \%$ of the population worldwide. Scientific evidence suggests that environmental factors are not solely accused for the development of this disease, genetic factors also play crucial role in predisposition to Sch. Conventional twin studies and population based family trials have already implicated the heredity in Sch with a frequency exceeding $80 \%$ and $60 \%$ respectively, establishing genetic traits underlying $\mathrm{Sch}^{2}$. Smoking is an important public health problem all around the world, causing death of almost six million people annually. Evidence supports that patients with severe psychiatric disorders tend to suffer from nicotine dependence (ND) ${ }^{3,4}$.

Oxidative stress occurs as a result of an abnormal redox regulation in which the intracellular concentrations of reactive oxygen species (ROS), exceed the antioxidant capacity ${ }^{5}$. It is generally assumed that a surplus of ROS is highly toxic and harms cellular elements, such as nucleic acids, proteins and lipids ${ }^{6}$. Oxidative damage leads to DNA base alterations, such as abasic sites, oxidized base modification, deamination, methylation, nucleotide deletion, nucleotide insertion, bulky abducts, single-strand breaks (SSBs), double-strand breaks (DSBs), inter- and intra-strand cross-links (ICLs), and DNA-protein cross-links?.

In vivo studies have reported that chronic administration of nicotine leads to the instability of pro-oxidant/antioxidant equilibrium in blood cells, blood plasma and tissues of rats ${ }^{8}$, while in vitro studies showed that nicotine heavily harms DNA and damages the prooxidant/antioxidant equilibrium in lymphocytes9. In addition, various experiments have also shown the relation between antioxidant status and symptom severity or psychosis ratings, that may associate the antioxidant defense system defects with Sch pathogenesis ${ }^{10}$. In mammalian cells, numerous predominant DNA repair mechanisms are well analyzed, such as direct repair, base excision repair (BER), nucleotide excision repair (NER), mismatch repair, homologous recombination repair (HR), and non-homologous end-joining repair $(\mathrm{NHEJ})^{11}$. XRCC4 gene is found on the chromosomal $5 \mathrm{q} 14.2$ and it is involved in precise end-joining of blunt DNA double strand breaks (DSBs) ${ }^{12}$. It was reported that genetic polymorphisms in DNA repair genes affect DNA repair ability and result in tendency to various disease types. Therefore, the purpose of this study was to investigate whether there is a relationship between XRCC4 rs6869366 variant and ND and Sch+ND risk.

\section{Methods}

\section{Subjects}

The study population involved a total of 104 patients diagnosed with Sch+ND, 133 subjects with ND and age, gender matched 70 healthy individuals as controls. The subjects were selected among the individuals from Bakirkoy Research and Training Hospital for Psychiatry Hospital, Istanbul Turkey and Yedikule Hospital for Chest Diseases and Thoracic Surgery Training and Research Hospital, Istanbul Turkey. Clinical diagnosis of Sch were made in strict accordance with DSM-IV criteria (Diagnostic and Statistical Manual of Mental Disorders, the fourth edition) based on SCID-I (Structured Clinical Interview for DSM-IV Axis I Disorders) by two independent psychiatrists ${ }^{13}$. The average amount of tobacco consumed per day was recorded for each participant. The severity of ND was evaluated by the scores on Heaviness of Smoking Index (HSI) and the Fagerström Test for Nicotine Dependence (FTND). The healthy control subjects were randomly recruited from relatives of patients in the Medicine Department, outpatient clinic, in the 
same hospital. Control subjects had a negative family or past history of any psychiatric disorders and had no family relationship to the present study patients. Informed written consent was obtained from the patients. The patient's information was anonymized before submission. The work was approved by Local Ethics Committee. All the procedures performed in the study were in accordance with the Declaration of Helsinki.

\section{Genotyping}

DNA was isolated with high salt DNA extraction method from peripheral blood samples ${ }^{14}$. Genotyping of XRCC4 rs6869366 variant was performed by polymerase chain reaction-restriction fragment length polymorphism (PCR-RFLP) assay according to previous paper ${ }^{15}$. The XRCC4 rs rs6869366 variant was determined using the following primers: $5^{\prime}$-GAT GCG AAC TCA AAG ATA CTG A-3', $5^{\prime}$-TGT AAA GCC AGT ACT CAA ACT T- $3^{\prime}, 55^{\circ} \mathrm{C}$ annealing temperature for the PCR reaction. The PCR product was digested with HincII enzyme. The digested PCR products were separated on a $2 \%$ agarose gel and stained with ethidium bromide for visualization under ultraviolet light (Figure 1). For quality control, the genotyping analysis was done blind as regards participants.

\section{Statistical analysis}

The SPSS version 14.0 for Windows (SPSS Inc., Chicago, IL; USA) was used for statistical analyses. The results were statistically analyzed by calculating the odds ratios (OR) and $95 \%$ confidence intervals (CI) using the $\chi^{2}$ test. Differences in XRCC4 rs6869366 genotype

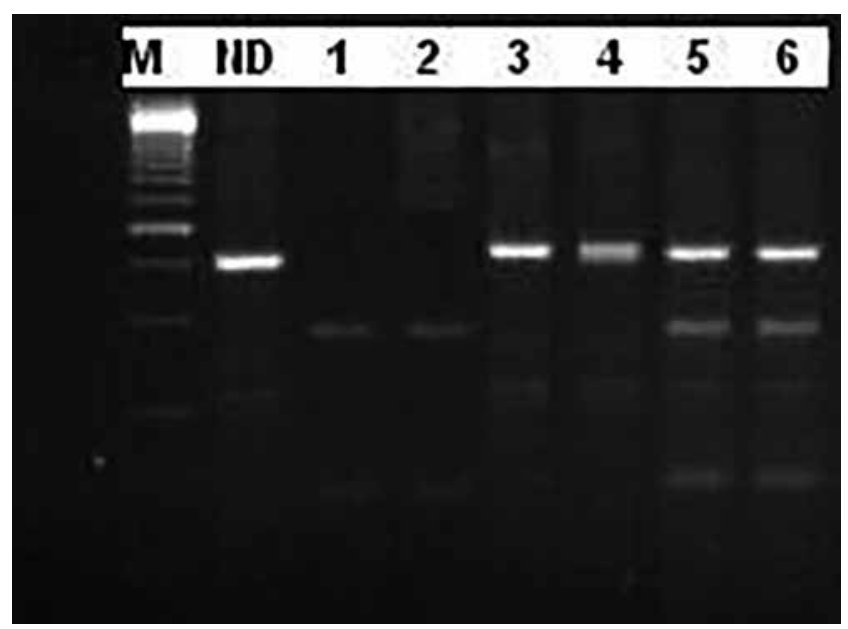

Figure 1. RFLP analysis of PCR products. Lane M: Marker; Lane ND: Non-digest PCR product; Lanes 1 and 2: homozygous TT; Lane 3 and 4: homozygous GG; Lanes 5 and 6: heterozygous GT. distribution between the patient and control groups were compared with chi-square test and, Fisher's exact test was used when needed. The Hardy-Weinberg Equilibrium (HWE) test was done to examine whether the allele and genotype frequencies in the studied groups remain constant from generation to generation in the absence of other evolutionary influences or not. All $p$-values were two sided, and a $p$-value was regarded as statistically significant when it less than 0.05 .

\section{Results}

For XRCC4 rs6869366 variant, $104 \mathrm{Sch}+\mathrm{ND}$ patients, 133 subjects with ND and 70 healthy controls were evaluated. The genotype and allele distributions of XRCC4 rs6869366 among the groups are showed in Table 1. It was found that XRCC4 rs6869366 TT genotype was significantly lower in Sch+ND and ND group compared to controls ( $\mathrm{p}=0.001$, OR: $28.333,95 \% \mathrm{Cl}$ : 6.434-124.762; $\mathrm{p}=0.001$, OR: $82.884,95 \% \mathrm{Cl}: 10.936-628.176$, respectively). The frequency of XRCC4 rs6869366 GG genotype was more common in the Sch+ND and ND group than the control group ( $\mathrm{p}=0.001, \mathrm{OR}: 0.112,95 \% \mathrm{Cl}$ : $0.056-0.227 ; \mathrm{p}=0.001$, OR: $0.071,95 \% \mathrm{Cl}: 0.035-0.143$, respectively). It was observed that the GT genotype was lower in ND group than the controls ( $\mathrm{p}=0.003$, OR: $0.826,95 \% \mathrm{Cl}$ : 1.459-5.474).

Frequency of XRCC4 rs6869366 G allele was higher in Sch+ND group than healthy control group ( $\mathrm{p}=0.001$, OR: $0.173,95 \% \mathrm{Cl}$ : $0.107-0.281$ ) while that of XRCC4 rs6869366 T alelle was lower in ND group than controls ( $\mathrm{p}=0.001$, OR:0.074, 95\%Cl:0.043-0.127).

\section{Discussion}

Cigarette smoke contains more than 7000 chemical compounds, along with a high levels of oxidants ${ }^{16}$. Cigarette smoke holds $10^{17}$ oxidant molecules per puff ${ }^{17}$. Nicotine is the major alkaloid present in cigarettes. It was first obtained as a distillate from tobacco, is detected in the blood of smokers ${ }^{18}$. Nicotine is among the most addicting substances and can induce oxidative stress in quantities similar to those in cigarette smoke, as shown in vitro and in vivo ${ }^{19,20}$ Chemical carcinogens and ROS can play a role in the accumulation of bulky adducts, SSBs, and DSBs, and several forms of nucleotide base modification or loss which can result in genomic instability.

Sch is a chronic, severe mental illness. The pathogenesis of this disease is unknown, however one generally accepted hypothesis for the etiology is that variations in more than one risk genes, each with a modest additive consequence, interacting with environmental and developmental factors, are involved in appearance of disease phenotype ${ }^{21}$. Between 40 and $90 \%$ of schizophrenics smoke. This ratio is remarkably higher than a several comparison populations such as those with other serious mental diseases ${ }^{22}$. Numerous studies have reported various indices of oxidative stress (increased cellular levels of ROS, disturbed antioxidant balance and increased oxidative damage) in blood, cerebrospinal fluid, and post-mortem brains from Sch patients compared with matched normal controls ${ }^{23}$. Further findings supporting a role of redox imbalances and oxidative stress in the

Table 1. Genotypes and allelic frequencies for XRCC4 rs6869366 polymorphism in Sch+ND, ND and control groups

\begin{tabular}{|c|c|c|c|c|c|c|}
\hline XRCC4 & Sch+ND & ND & Controls & $\mathrm{OR}^{*}$ & $\% 95 \mathrm{Cl}^{*}$ & $p$ \\
\hline Genotypes & $n=104(\%)$ & $n=133(\%)$ & $\mathrm{n}=70(\%)$ & & & \\
\hline TT & $2(1.93)$ & $1(0.75)$ & $27(38.58)$ & $\begin{array}{l}28.333^{a} \\
82.884 b\end{array}$ & $\begin{array}{c}6.434-124.762^{a} \\
10.936-628.176^{b}\end{array}$ & $\begin{array}{l}0.001 \mathrm{a} \\
0.001 \mathrm{~b}\end{array}$ \\
\hline GT & $25(24.04)$ & $23(17.29)$ & $26(37.14)$ & $\begin{array}{l}1.876^{a} \\
2.826^{b}\end{array}$ & $\begin{array}{l}0.964-3.618^{a} \\
1.459-5.474 b\end{array}$ & $\begin{array}{l}0.089^{a} \\
0.003^{b}\end{array}$ \\
\hline GG & 77 (74.03) & 109 (81.96) & $17(24.28)$ & $\begin{array}{l}0.112^{\mathrm{a}} \\
0.071^{\mathrm{b}}\end{array}$ & $\begin{array}{l}0.056-0.227 \text { a } \\
0.035-0.143^{b}\end{array}$ & $\begin{array}{l}0.001^{\mathrm{a}} \\
0.001^{\mathrm{b}}\end{array}$ \\
\hline \multicolumn{7}{|l|}{ Alleles } \\
\hline $\mathbf{T}$ & $29(13.94)$ & $25(9.39)$ & $80(57.14)$ & $0.074 b$ & $0.043-0.127 \mathrm{~b}$ & $0.001 \mathrm{~b}$ \\
\hline $\mathbf{G}$ & $179(86.06)$ & 241 (90.61) & $60(42.86)$ & $0.173^{a}$ & $0.107-0.281 a$ & $0.001 \mathrm{a}$ \\
\hline
\end{tabular}

Fisher's Exact Test, a:Sch + ND versus control group; b: ND versus control group.

The results that are statistically significant are shown in *boldface. 
development of Sch arise from several animal models, which imply that increased oxidative stress during sensitive windows of brain development and maturation is related to the subsequent occurrence of Sch-linked brain and behavioral abnormalities ${ }^{24,25}$. Brain tissue is particularly vulnerable to oxidative stress because it has a high rate of oxidative metabolic activity, high oxygen consumption, relatively low concentrations of antioxidant enzymes, and a neural network that is vulnerable to damage ${ }^{26}$.

The DNA repair system acts as a cellular defense mechanism against DNA damage due to mostly oxidative stress. Altered or deficient bases and SSBs are usually fixed through the BER. There are two major mechanisms for DSBs repair which are called homologous recombination and NHEJ. The NHEJ is the main pathway to repair DSBs in mammals ${ }^{27}$. To evaluate the cellular ability for DNA repair in Sch patients, DNA damage under basal conditions and due to cellular stressors was measured. Flow cytometric analysis of the DNA DSB marker $\gamma \mathrm{H} 2 \mathrm{AX}$ in immortalized lymphoblasts from Sch patients showed a significantly increased baseline levels of $\gamma \mathrm{H} 2 \mathrm{AX}$ in untreated cells, and a decreased $\gamma \mathrm{H} 2 \mathrm{AX}$ response upon irradiation with 5 Gray 28 . In the NHEJ pathway, a relatively small number of essential repair proteins regulate the DSB repair, such as XRCC4.

$X R C C 4$ encodes a nuclear phosphoprotein that multimerizes and interacts with DNA Ligase 4 and DNA-dependent protein kinase, involving in the NHEJ pathway ${ }^{29}$. The XRCC4 is expressed in brain. In mice, lack of XRCC4 is lethal in embryos leading to a massive neuronal apoptosis, and XRCC4 has been reported to act with p53 in the regulation of apoptosis, suggesting that XRCC4 is important for genomic stability and for the inhibition of tumors ${ }^{30}$. In the genetargeting mutation mice model, XRCC4 gene inactivation results in late embryonic mortality along with defective lymphogenesis and defective neurogenesis characterized by broad apoptotic death of newly produced postmitotic neurons ${ }^{31}$. These results showed that differentiating lymphocytes and neurons rigorously necessitate the XRCC4 end-joining proteins. Genome-wide scan showed that $5 \mathrm{q} 14.1$ is related with Sch risk, and the gene encoding XRCC4 is found in this region. Several genetic variants in the XRCC4 have been reported in humans. One of them is a variable number tandem repeat (VNTR) variant in intron 3 of the XRCC4 gene. The other, the rs6869366 SNP is found at 1394 bp upstream of the XRCC4 gene, and is involved in regulating gene expression ${ }^{32}$.

It is generally believed that variations of the sequence of the promoter region are linked with a altered level of gene expression. Thus, this type of polymorphism may affect the expression level of the gene. Variants of these specific SNPs might result in an abnormal capacity for protein products, causing several deficiencies. When a DNA repair gene is incapable of normal expression, its downstream genes are directly influenced, leading to the dysfunction of the whole pathway. Therefore, these variants result in a decreased capacity of the repair system and increase the risk of cell pathogeneses.

Considering the higher smoking rates among Sch patients and the close association between nicotine and oxidative stress, and the crucial role of free radicals in the pathophysiology of Sch, we hypothesized that whether XRCC4 rs6869366 variant is related with both ND group and ND+Sch group in a Turkish cohort. As far as we know, there has been no study conducted about the correlation between XRCC4 rs6869366 variant and both ND and ND+Sch.

Previously, it was shown that frequencies of XRCC4 rs6869366 TG+GG genotypes were higher in patients with autism spectrum disorder than the controls ${ }^{33}$. He et al. reported that patients who smoked and carried the XRCC4 $\mathrm{rs} 6869366 \mathrm{G}$ allele had an increased risk for non small cell lung cancer (NSCLC) ${ }^{34}$. In a study conducted on the patients with lung cancer, Hsu et al. demonstrated that people with rs 6869366 GT genotype and smoking habit present the highest risk of lung cancer than other groups ${ }^{35}$. However in a study investigating urothelial bladder cancer, Mittal et al. found no association between XRCC4 rs6869366 variant and smoking ${ }^{36}$. We have previously demonstrated that XRCC4 intron 3 VNTR variant ID genotype was higher in ND group than in healthy control group ${ }^{37}$. In present study, we found that the frequency of XRCC4 rs6869366
GG genotype and G allele were more common in the both ND group and $\mathrm{Sch}+\mathrm{ND}$ group than the control group $(\mathrm{p}=0.001$ and $\mathrm{p}=0.001$, respectively). XRCC4 rs6869366 TT genotype and T allele were significantly lower in ND and Sch+ND group compared to the controls ( $\mathrm{p}=0.001$ and $\mathrm{p}=0.001$, respectively). Furthermore, we found that XRCC4 rs6869366 GT genotype was lower in ND group than control group $(p=0.003)$. The absence of this significance in the $\mathrm{Sch}+\mathrm{ND}$ group was attributed to heterozygous disadvantage.

In conclusion, for the first time, we showed that XRCC4 functional rs6869366 variant plays a role in the risk of ND and $\mathrm{ND}+\mathrm{Sch}$ in a Turkish population. Our results suggested that XRCC4 rs6869366 GG genotype and $\mathrm{G}$ allele might be a susceptibility factor for both ND and Sch+ND. It stresses that this DNA repair mechanism has a role in the etiopathogenesis of Sch and ND, and that further studies in this issue should be done in different populations.

\section{References}

1. Rao W, Zhou N, Zhang H, Liu R, Zhang S, Su Y, et al. A case-control study of the association between polymorphisms in the fibrinogen alpha chain gene and schizophrenia. Dis Markers. 2017;2017:3104180.

2. Feng Y, Cheng D, Zhang C, Li Y, Zhang Z, Wang J, et al. Association between ErbB4 single nucleotide polymorphisms and susceptibility to schizophrenia: A meta-analysis of case-control studies. Medicine (Baltimore). 2017;96(8):e5920.

3. de Leon J, Tracy J, McCann E, McGrory A, Diaz FJ. Schizophrenia and tobacco smoking: a replication study in another US psychiatric hospital. Schizophr Res. 2002;56(1-2):55-65.

4. Pawlina MMC, Rondina RC, Espinosa MM, Botelho C. Nicotine dependence and levels of depression and anxiety in smokers in the process. Rev Psiq Clín. 2014;41(4):101-5.

5. Mitra S, Natarajan R, Ziedonis D, Fan X. Antioxidant and anti-inflammatory nutrient status, supplementation, and mechanisms in patients with schizophrenia. Prog Neuropsychopharmacol Biol Psychiatry. 2017;78:1-11.

6. Pizarro JG, Folch J, Vazquez De la Torre A, Verdaguer E, Junyent F, Jordán J, et al. Oxidative stress-induced DNA damage and cell cycle regulation in B65 dopaminergic cell line. Free Radic Res. 2009;43(10):985-94.

7. Yan J, Wang X, Tao H, Deng Z, Yang W, Lin F. Meta-Analysis of the Relationship between XRCC1-Arg399Gln and Arg280His Polymorphisms and the Risk of Prostate Cancer. Sci Rep. 2015;5:9905.

8. Suleyman H, Gumustekin K, Taysi S, Keles S, Oztasan N, Aktas O, et al. Beneficial effects of Hippophae rhamnoides L. on nicotine induced oxidative stress in rat blood compared with vitamin E. Biol Pharm Bull. 2002;25(9):1133-6.

9. Sudheer AR, Muthukumaran S, Devipriya N, Menon VP. Ellagic acid, a natural polyphenol protects rat peripheral blood lymphocytes against nicotine-induced cellular and DNA damage in vitro: with the comparison of N-acetylcysteine. Toxicology. 2007;230(1):11-21.

10. Wu JQ, Kosten TR, Zhang XY. Free radicals, antioxidant defense systems, and schizophrenia. Prog Neuropsychopharmacol Biol Psychiatry. 2013;46:200-6

11. Sancar A, Lindsey-Boltz LA, Unsal-Kaçmaz K, Linn S. Molecular mechanisms of mammalian DNA repair and the DNA damage checkpoints. Annu Rev Biochem. 2004;73:39-85.

12. Wang Y, Wang L, Li X, Liu B, Zhao Q, Chen P, et al. Polymorphisms of XRCC4 are involved in reduced colorectal cancer risk in Chinese schizophrenia patients. BMC Cancer. 2010;10:523.

13. American Psychiatric Association. Text Revision. 4th. Diagnostic and Statistical Manual of Mental Disorders. Washington, DC: American Psychiatric Association; 2000.

14. Miller SA, Dykes DD, Polesky HF. A simple salting out procedure for extracting DNA from human nucleated cells. Nucleic Acids Res. 1988;16(3):1215

15. Cifci S, Yilmaz M, Pehlivan M, Sever T, Okan V, Pehlivan S. DNA repair genes polymorphisms in multiple myeloma: no association with XRCC1 (Arg399Gln) polymorphism, but the XRCC4 (VNTR in intron 3 and G-1394T) and XPD (Lys751Gln) polymorphisms is associated with the disease in Turkish patients. Hematology. 2011;16(6):361-7.

16. Faux SP, Tai T, Thorne D, Xu Y, Breheny D, Gaca M. The role of oxidative stress in the biological responses of lung epithelial cells to cigarette smoke. Biomarkers. 2009;14 Suppl 1:90-6. 
17. Donohue JF. Ageing, smoking and oxidative stress. Thorax. 2006;61(6):461-2.

18. Hammond D, Collishaw NE, Callard C. Secret science: tobacco industry research on smoking behaviour and cigarette toxicity. Lancet. 2006;367:781-7.

19. Solak ZA, Kabaroglu C, Cok G, Parildar Z, Bayindir U, Ozmen D, et al. Effect of different levels of cigarette smoking on lipid peroxidation, glutathione enzymes and paraoxonase 1 activity in healthy people. Clin Exp Med. 2005;5(3):99-105.

20. Rytilä P, Rehn T, Ilumets H, Rouhos A, Sovijärvi A, Myllärniemi M, et al. Increased oxidative stress in asymptomatic current chronic smokers and GOLD stage 0 COPD. Respir Res. 2006;7(1):69.

21. Harrison PJ, Weinberger DR. Schizophrenia genes, gene expression, and neuropathology: on the matter of their convergence. Mol Psychiatry. 2005;10(1):40-68.

22. Kelly C, McCreadie RG. Smoking habits, current symptoms, and premorbid characteristics of schizophrenic patients in Nithsdale, Scotland. Am J Psychiatry. 1999;156(11):1751-7.

23. Mahadik SP, Pillai A, Joshi S, Foster A. Prevention of oxidative stressmediated neuropathology and improved clinical outcome by adjunctive use of a combination of antioxidants and omega- 3 fatty acids in schizophrenia. Int Rev Psychiatry. 2006;18(2):119-31.

24. Cabungcal JH, Counotte DS, Lewis E, Tejeda HA, Piantadosi P, Pollock $\mathrm{C}$, et al. Juvenile antioxidant treatment prevents adult deficits in a developmental model of schizophrenia. Neuron. 2014;83(5):1073-84.

25. Cabungcal JH, Steullet P, Morishita H, Kraftsik R, Cuenod M, Hensch TK, et al. Perineuronal nets protect fast-spiking interneurons against oxidative stress.Proc Natl Acad Sci U S A. 2013;110(22):9130-5.

26. Bošković M, Vovk T, Kores Plesničar B, Grabnar I. Oxidative stress in schizophrenia. Curr Neuropharmacol. 2011;9(2):301-12.

27. Li Z, Otevrel T, Gao Y, Cheng HL, Seed B, Stamato TD, et al. The XRCC4 gene encodes a novel protein involved in DNA double-strand break repair and V(D)J recombination. Cell. 1995;83(7):1079-89.
28. Catts VS, Catts SV, Jablensky A, Chandler D, Weickert CS, Lavin MF. Evidence of aberrant DNA damage response signalling but normal rates of DNA repair in dividing lymphoblasts from patients with schizophrenia. World J Biol Psychiatry. 2012;13(2):114-25.

29. Hayden PJ, Tewari P, Morris DW, Staines A, Crowley D, Nieters A, et al. Variation in DNA repair genes XRCC3, XRCC4, XRCC5 and susceptibility to myeloma. Hum Mol Genet. 2007;16(24):3117-27.

30. Gao Y, Ferguson DO, Xie W, Manis JP, Sekiguchi J, Frank KM, et al Interplay of p53 and DNA-repair protein XRCC4 in tumorigenesis, genomic stability and development. Nature. 2000;404(6780):897-900.

31. Chiu CF, Wang CH, Wang CL, Lin CC, Hsu NY, Weng JR, et al. A novel single nucleotide polymorphism in XRCC4 gene is associated with gastric cancer susceptibility in Taiwan. Ann Surg Oncol. 2008;15:514-8.

32. Wu KH, Wang CH, Yang YL, Peng CT, Lin WD, Tsai FJ, et al. Significant association of XRCC4 single nucleotide polymorphisms with childhood leukemia in Taiwan. Anticancer Res. 2010;30(2):529-33.

33. Dasdemir S, Guven M, Pekkoc KC, Ulucan H, Dogangun B, Kirtas E, et al. DNA repair gene XPD Asp312Asn and XRCC4 G-1394T polymorphisms and the risk of autism spectrum disorder. Cell Mol Biol (Noisy-le-grand). 2016;62(3):46-50.

34. He F, Chang SC, Wallar GM, Zhang ZF, Cai L. Association of XRCC3 and XRCC4 gene polymorphisms, family history of cancer and tobacco smoking with non-small-cell lung cancer in a Chinese population: a case-control study. J Hum Genet. 2013;58(10):679-85.

35. Hsu NY, Wang HC, Wang CH, Chang CL, Chiu CF, Lee HZ, et al. Lung cancer susceptibility and genetic polymorphism of DNA repair gene XRCC4 in Taiwan. Cancer Biomark. 2009;5(4):159-65.

36. Mittal RD, Gangwar R, Mandal RK, Srivastava P, Ahirwar DK. Gene variants of XRCC4 and XRCC 3 and their association with risk for urothelial bladder cancer. Mol Biol Rep. 2012;39(2):1667-75.

37. Pehlivan S, Uysal MA, Aydin PC, Pehlivan M, Nursal AF, Yavuzlar H, et al. eNOS and XRCC4 VNTR variants contribute to formation of nicotine dependence and/or schizophrenia. Bratisl Lek Listy. 2017;118(8):467-71. 